Check for updates

Cite this: Chem. Commun., 2020, 56,8027

Received 10th February 2020

Accepted 4th March 2020

DOI: $10.1039 / \mathrm{d} 0 \mathrm{cc} 01072 \mathrm{c}$

rsc.li/chemcomm

\section{Air and water stable secondary phosphine oxides as diazaphospholene precatalysts $\dagger$}

\author{
Travis Lundrigan, ${ }^{a}$ Chieh-Hung Tien, ${ }^{a}$ Katherine N. Robertson $\left(\mathbb{D}^{\mathrm{b}}{ }^{\mathrm{b}}\right.$ and \\ Alexander W. H. Speed (D)*a
}

\begin{abstract}
Air-stable secondary phosphine oxides (SPOs) are readily formed from diazaphospholene bromides. In the presence of pinacolborane, these SPOs are transformed into catalytically active diazaphospholene hydrides. A silyl triflate transforms the SPOs into phosphenium triflates. The use of diazaphospholene SPOs as reduction reaction precatalysts was validated by imine reduction, conjugate reduction, pyridine hydroboration, and asymmetric reduction.
\end{abstract}

Diazaphospholenes have recently emerged as a class of catalyst for reduction reactions. Gudat showed that highly air-sensitive diazaphospholene hydrides were stoichiometric reducing reagents for aldehydes, ketones, and conjugate acceptors. ${ }^{1}$ Kinjo showed that ammonia borane could regenerate a diazaphospholene hydride in the reduction of an azo compound, allowing catalysis with diazaphospholenes. ${ }^{2 a}$ Kinjo then showed that pinacolborane (HB(pin)) and diphenylsilane could be terminal reductants in aldehyde and carbon dioxide reductions, respectively. Importantly, pinacolborane transformed an alkoxydiazaphospholene to a diazaphospholene hydride in Kinjo's work (eqn (1), Fig. 1). ${ }^{2 b, c}$ Our research group has exploited the alkoxydiazaphospholene intermediate from Kinjo's aldehyde-reduction catalytic cycle as a precatalyst for diazaphospholenes. We used this system to catalyze imine reductions and render Gudat's conjugate reductions catalytic. ${ }^{3 a}$ Kinjo and our group separately reported that diazaphospholenes catalyze the reduction of pyridines, with the distinct difference that our group used a neutral precatalyst, while Kinjo used a cationic triflate. ${ }^{4}$ We subsequently employed the pre-catalyst strategy to form a chiral diazaphospholene for imine reduction. ${ }^{3 b}$ Cramer disclosed an elegant chiral diazaphospholene precatalyst based on an alkoxydiazaphospholene for conjugate reduction and Claisen reactions. ${ }^{5}$ Other reported

\footnotetext{
${ }^{a}$ Department of Chemistry, Dalhousie University, Halifax, Nova Scotia, B3H 4R2, Canada.E-mail: aspeed@dal.ca

${ }^{b}$ Department of Chemistry, Saint Mary's University, Halifax, Nova Scotia B3H 3C3, Canada

$\dagger$ Electronic supplementary information (ESI) available. CCDC 1981976. For ESI and crystallographic data in CIF or other electronic format see DOI: 10.1039/d0cc01072c
}

Previous diazaphospholene (and arsene) pre-catalyst strategies:

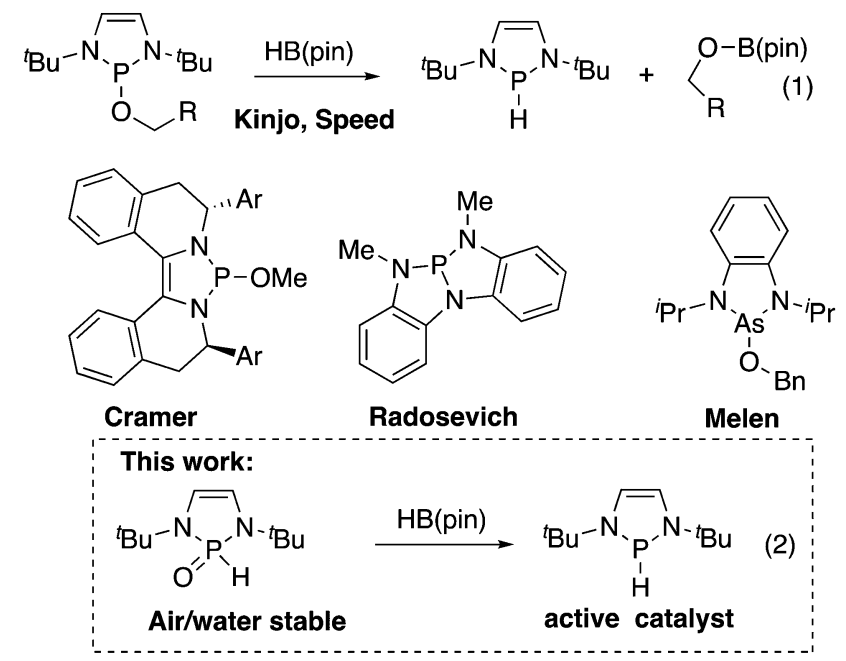

Fig. 1 Comparison of diazaphospholene precatalysts.

systems relevant to diazaphospholene pre-catalysts include Radosevich's trisamidophosphine that forms a diazaphospholene in the presence of $\mathrm{HB}(\mathrm{pin}){ }^{6}$ and diazaarsolenes bearing alkoxy substituents reported by Melen. Arsenic hydrides have not been isolated from these systems, however these arsenic catalysts do engage in reduction catalysis in analogy to the dizazphospholene systems. ${ }^{7}$ Yang and Cheng showed that diazaphospholenes are the most hydridic neutral compounds yet quantified on the Mayr nucleophilicity scale, promising a rich future for diazaphospholenes as reduction catalysts and reagents. ${ }^{8}$

With this intense interest in diazaphospholenes, further developments to increase the accessibility of these catalysts in organic synthesis is warranted. This work shows that the secondary phosphine oxide (SPO) hydrolysis products of diazaphospholene alkoxides or halides are air and water stable, can be purified by silica gel chromatography, and can serve as precatalysts for diazaphospholene hydrides (eqn (2), Fig. 1) and the corresponding phosphenium triflates. 


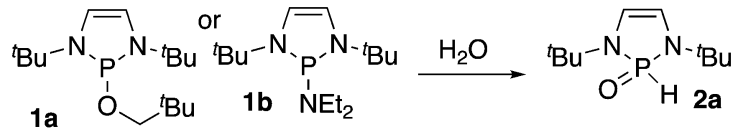

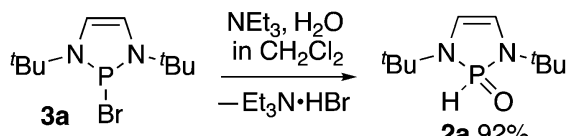

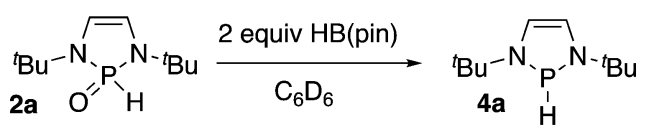

Scheme 1 Synthesis of a diazaphospholene SPO, and its transformation to hydride.

During our initial investigations of diazaphospholenes, we observed that samples of diazaphospholene precatalyst 1a in standard NMR tubes hydrolyzed to SPO 2a because of the incursion of water (Scheme 1). ${ }^{3}$ SPOs of diazaphospholenes have been rationally synthesized as ligands for metals via hydrolysis of amidodiazaphospholene $\mathbf{1 b} .^{9}$ We also noted that when $\mathrm{HB}$ (pin) was present with 1a, SPO formation was not observed on the same timeframe. We considered that $\mathrm{HB}(\mathrm{pin})$ could either be scavenging the water or could be reducing the SPO. While this work was in progress, Webster and co-workers reported the reduction of dialkyl and diaryl SPOs directly to uncomplexed phosphines using pinacolborane at room temperature. ${ }^{10}$

In a more direct synthesis of $2 \mathbf{a}$ we avoided the preparation of intermediate $\mathbf{1 a}$ or $\mathbf{1 b}$ by combining diazaphospholene bromide 3a with triethylamine in dichloromethane followed by addition of water to afford SPO $2 \mathbf{a}$. Compound $\mathbf{2 a}$ is a solid that was stable to column chromatography in air (Scheme 1). NMR spectral data matched that previously reported for $2 \mathbf{a}^{9 a}$ Additionally, a crystal of 1a grown from ethyl acetate/hexanes has the same unit cell as that previously reported for crystals of 2a. ${ }^{9, b} \mathrm{HB}$ (pin) transforms $\mathbf{2 a}$ to hydride $\mathbf{4 a}$ in various solvents, including benzene- $d 6$, and THF. While 1 equivalent of $\mathrm{HB}(\mathrm{pin})$ was sufficient for the transformation, the reaction proceeded significantly faster when greater than 1 equivalent of $\mathrm{HB}(\mathrm{pin})$ was used.

We used 2a in reductions employing $\mathrm{HB}(\mathrm{pin})$ that are known to be catalyzed by diazaphospholenes, and have been documented to not undergo an uncatalyzed reaction with $\mathrm{HB}(\mathrm{pin})$ to validate the function of $\mathbf{2 a}$ as a precatalyst (Scheme 2). Imine $\mathbf{5 a}$ was reduced to the corresponding amine with $\mathrm{HB}(\mathrm{pin})$ in the presence of $1 \mathrm{~mol} \%$ of $2 \mathrm{a}^{3 a}$ Chalcone 6 was reduced to compound 7 with $1 \mathrm{~mol} \%$ of $2 \mathrm{a}^{3 a, 5 a, 11}$ Precatalyst $2 \mathrm{a}$ also effected the reduction of pyridines with $\mathrm{HB}(\mathrm{pin})$. Nicotinonitrile $\mathbf{8 a}$ was reduced to dihydropyridine $\mathbf{9 a}$, while 3-acetylpyridine $\mathbf{8 b}$ was reduced to dihydropyridine $\mathbf{9 b}$ without reduction of the ketone. These results show similar chemoselectivity and selectivity to previous pyridine reductions performed with precatalyst $1 \mathbf{1 a}^{4}$

We subsequently explored the chemistry of a chiral SPO precatalyst (Scheme 3). Compound $\mathbf{2 b}$ was prepared from the hydrolysis of the corresponding bromide and was also an air and water stable substance that could be purified by silica gel chromatography. ${ }^{3 b}$ In a further simplification of the procedure,

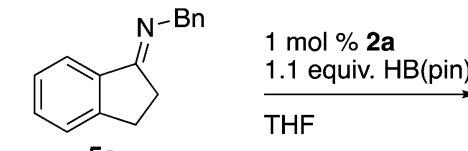<smiles>c1ccc(CNC2CCC3CCCC32)cc1</smiles><smiles>CCOC(=O)C=Cc1ccc(C(=O)c2ccccc2)cc1</smiles><smiles>Cc1ccc(CCC(=O)c2ccccc2)cc1</smiles>

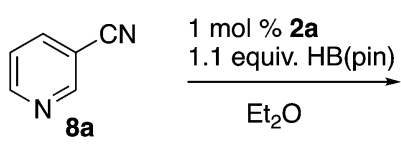

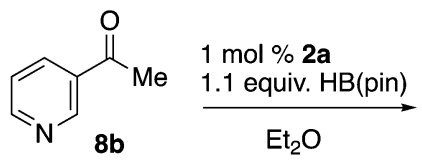<smiles></smiles><smiles></smiles>

Scheme 2 Reduction reactions with SPO precatalyst 2 a.

isolation of $\mathbf{3 b}$ could be completely avoided. Diimine $\mathbf{1 0}$ was cyclized with $\mathrm{PBr}_{3}$ and cyclohexene according to MacDonald and co-workers' procedure for diazaphospholene generation. ${ }^{12}$ After one hour, triethylamine and water were added directly to the reaction mixture. After aqueous work-up and chromatography, 2b was obtained in good yield. This procedure allowed preparation of $\mathbf{2 b}$ in one pot from starting material $\mathbf{1 0}$, without the isolation of any air-sensitive intermediates. Prior NMR spectroscopy of $\mathbf{3 b}$ had shown equivalence of the naphthylethyl sidechains and backbone protons, implying a $C_{2}$ symmetric structure, which strongly suggests that the $\mathrm{P}-\mathrm{Br}$ bond is ionized in solution, resulting in planarization of the phosphorus. ${ }^{3 b, 13}$ NMR spectroscopy of $\mathbf{2 b}$ shows less symmetry: the naphthylethyl side-chains and backbone protons of the diazaphospholene are now inequivalent, a consequence of the breaking of $C_{2}$ symmetry because of the distinct $\mathrm{H}$ and $\mathrm{O}$ phosphorus substituents in the SPO. X-ray crystallography confirmed the structure of $\mathbf{2 b}$. $^{14}$

Asymmetric reduction reactions were explored with chiral precatalyst $\mathbf{2 b}$ (Scheme 4). Reduction of imine $\mathbf{5 b}$ to amine $\mathbf{6 b}$ (eqn (1), Scheme 4) proceeded with comparable enantioselectivity to that previously observed with chiral diazaphospholenes with an $85: 15$ e.r. at room temperature, and an increase to $92: 8$ e.r. at $-35{ }^{\circ} \mathrm{C} .{ }^{16}$ A limitation for the use of $\mathbf{2 b}$ was revealed when

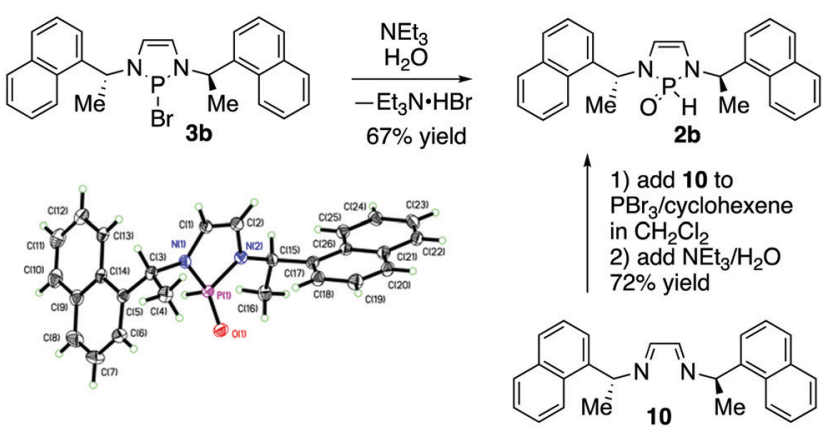

Scheme 3 Preparation and X-ray structure of chiral SPO precatalyst $\mathbf{2 b}$ 
<smiles>c1ccc2cc(C3=NCCC3)ccc2c1</smiles>

$5 \mathrm{~mol} \% \mathbf{2 b}$ 1.1 equiv. $\mathrm{HB}$ (pin)

THF, $-35^{\circ} \mathrm{C}$

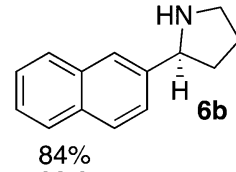

(1)

$92: 8$ e.r.<smiles>c1ccc2c(c1)sc1c(C3=NCCC3)cccc12</smiles>

$5 \mathrm{~mol} \% \mathbf{2 b}$ 1.1 equiv. $\mathrm{HB}$ (pin) THF, $20^{\circ} \mathrm{C}$

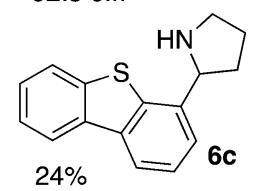

$52: 48$ e.r.

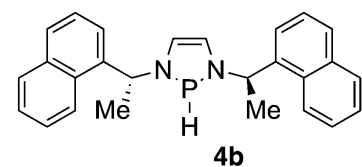

Scheme 4 Asymmetric catalysis with SPO precatalyst $\mathbf{2 b}$.

sterically hindered imine $\mathbf{5 c}$ gave a low yield of essentially racemic product $\mathbf{6 c}$ under these conditions (eqn (2), Scheme 4). To further understand these distinctive results, we repeated the experiments in NMR tubes and observed the reaction progress by ${ }^{11} \mathrm{~B}$ and ${ }^{31} \mathrm{P}$ NMR spectroscopy. After the components were mixed, the reaction of eqn (1) showed almost complete consumption of $\mathrm{HB}$ (pin) according to the ${ }^{11} \mathrm{~B}$ NMR spectrum after 5 minutes. The ${ }^{31} \mathrm{P}$ NMR spectrum of this reaction showed a mixture of precatalyst $\mathbf{2 b}$ and hydride $\mathbf{4} \mathbf{b}$. The reaction of eqn (2) exhibited substantially different behavior. The ${ }^{11} \mathrm{~B}$ NMR spectrum showed essentially no conversion after both 5 minutes and two hours, with mostly unreacted $\mathrm{HB}(\mathrm{pin})$ present. At both the 5 minute and two hour mark, the ${ }^{31} \mathrm{P}$ NMR spectrum of the reaction of eqn (2) showed a relatively complex mixture of phosphorus containing products, including putative $\mathbf{4 c}$, and $\mathrm{PH}_{3}$. These endocyclic cleavage products have previously been noted in the decomposition of diazaphospholenes, and do not appear to be catalytically active in imine reduction. ${ }^{3}$ Accordingly, with a readily reduced substrate such as $\mathbf{5 b}$, pre-catalyst activation and imine reduction occur, while with a challenging substrate such as $\mathbf{5 c}$, reduction does not occur before decomposition of the catalyst. The observed formation of $\mathbf{6 c}$ in the reaction of eqn (2) is presumably due to an uncatalyzed reduction of the imine with $\mathrm{HB}($ pin) mediated by the water introduced during the quenching of the reaction. ${ }^{15}$

Our recently reported cationic diazaphospholene catalysts are able to reduce substrate $\mathbf{5 c}$ in a highly enantioselective manner, showing that $\mathbf{2 b}$ has inferior reactivity. ${ }^{16}$

Given this limitation, we sought to determine if $\mathbf{2 a}$ and $\mathbf{2 b}$ could be used to generate phosphenium cations in situ, enabling access to more active phosphenium triflate reduction catalysts. Exposure of $\mathbf{2 a}$ or $\mathbf{2 b}$ to TBS triflate in dry chloroform- $d$ on an NMR scale immediately resulted in the formation of phosphenium ions 10a and 10b, as evidenced by appearance of a signal in the ${ }^{31} \mathrm{P}$ NMR spectrum at $+202.3 \mathrm{ppm}$ for $2 \mathrm{a}$, and $208.6 \mathrm{ppm}$ for 2b (Scheme 5). Additionally, the formerly diastereotopic naphthylethyl groups in $\mathbf{2 b}$ became equivalent in the ${ }^{1} \mathrm{H}$ NMR spectrum, indicating the generation of $C_{2}$ symmetry by planarization of the phosphorus centre. The mixture containing 2a proved competent in

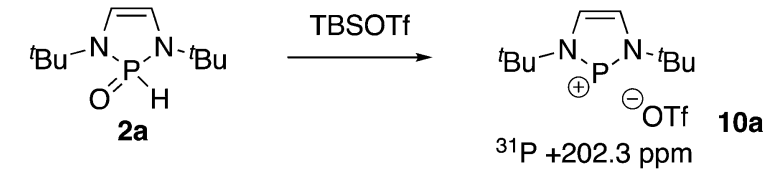

$$
\mathrm{Map}_{\mathbf{2 b}} \mathrm{O}_{\mathrm{O}}^{\mathrm{N}} \mathrm{Me}_{\mathrm{Me}}^{\mathrm{Nap}}
$$

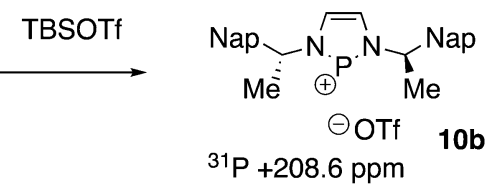

1) $5 \mathrm{~mol} \% \mathbf{2 a}$

$5 \mathrm{~mol} \%$ TBSOTf<smiles>c1cnc2c(c1)CCC2</smiles>

2) add $\mathrm{HB}($ pin)

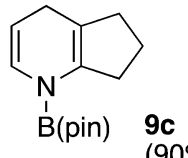

$(90 \%)$

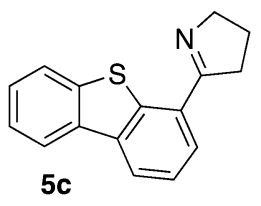

\begin{tabular}{l} 
1) $5 \mathrm{~mol} \% \mathbf{2 b}$ \\
$5 \mathrm{~mol} \% \mathrm{TBSOTf}$ \\
2) add HB(pin) \\
\hline THF, $20{ }^{\circ} \mathrm{C}$
\end{tabular}

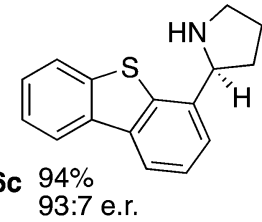

Scheme 5 Catalysis with phosphenium cations generated from SPO precatalysts $\mathbf{2 a}$ and $\mathbf{2} \mathbf{b}$.

the reduction of pyridine $\mathbf{8 c}$ to the dihydropyridine $9 \mathbf{c}$. Pyridines such as $\mathbf{8 c}$ with no electron withdrawing group would not be expected to readily undergo reduction with neutral diazaphospholenes. ${ }^{5 b}$ Kinjo has effected reductions of such pyridines employing phosphenium cations. ${ }^{5 a}$ In the chiral system, exposure of $\mathbf{2 b}$ to TBS triflate, followed by addition of imine $\mathbf{5 c}$, and $\mathrm{HB}$ (pin) restored asymmetric induction with $\mathbf{5 c}$, leading to selective formation of 6c. This contrasts with the absence of selectivity observed with precatalyst $\mathbf{2 b}$ for the reduction of $\mathbf{5 c}$ in the absence of the silyl triflate. The observed reactivity and selectivity are close to that previously observed in the reduction of compound $\mathbf{5 c}$ catalyzed by isolated phosphenium ion 10b, and it would be expected that the large scope of substrates reduced by isolated 10b could also be prepared under these in situ conditions. In addition, endocyclic cleavage of $\mathbf{1 0 b}$ with excess $\mathrm{HB}($ pin) has never been noted, enabling the reduction of more challenging substrates such as $\mathbf{5 c}$ to compete with catalyst decomposition. ${ }^{16}$

In conclusion, we have validated the use of SPOs derived from diazaphospholenes as precatalysts for the catalytically active diazaphospholene hydrides. Given growing interest in diazaphospholenes, the demonstration that secondary phosphine oxides can serve as bench-purifiable and air stable precatalysts will further help to popularize diazaphospholene chemistry. The stability of these entities to chromatography will enable the separation of diazaphospholene precursors from complex product mixtures, potentially allowing access to diazaphospholenes that cannot currently be accessed cleanly. We have also demonstrated generation of phosphenium cations from diazaphospholene SPOs, showing how these highly active asymmetric reduction catalysts can also be accessed from airstable precursors. 
Financial support from NSERC (Discovery Grant and I2I Grant), the Killam Foundation (C.-H. T.) are acknowledged. Dr Mike Lumsden and Mr Xiao Feng are thanked for assistance with NMR spectroscopy and mass spectrometry, respectively.

\section{Conflicts of interest}

The authors declare the following competing financial interest(s): Dalhousie University has filed patents on chiral phosphenium triflates and secondary phosphine oxides for asymmetric imine reduction, from which royalty payments may be derived.

\section{References}

1 (a) D. Gudat, A. Haghverdi and M. Nieger, Angew. Chem., Int. Ed., 2000, 39, 3084; (b) S. Burck, D. Gudat, M. Nieger and W. W. Du Mont, J. Am. Chem. Soc., 2006, 128, 3946; (c) D. Gudat, Dalton Trans., 2016, 45, 5896; (d) D. Gudat, Diazaphospholene Chemistry. In Encyclopedia of Inorganic and Bioinorganic Chemistry, Online, ed. R. A. Scott, John Wiley and Sons, Hoboken, NJ, 2nd edn, 2018.

2 (a) C. C. Chong, H. Hirao and R. Kinjo, Angew. Chem., Int. Ed., 2014, 53, 3342; (b) C. C. Chong, H. Hirao and R. Kinjo, Angew. Chem., Int. Ed., 2015, 54, 190; (c) C. C. Chong and R. Kinjo, Angew. Chem., Int. Ed., 2015, 53, 12116.

3 (a) M. R. Adams, C.-H. Tien, B. S. N. Huchenski, M. J. Ferguson and A. W. H. Speed, Angew. Chem., Int. Ed., 2017, 56, 6268; (b) M. R. Adams,
C.-H. Tien, R. McDonald and A. W. H. Speed, Angew. Chem., Int. Ed., 2017, 56, 16660.

4 (a) B. Rao, C. C. Chong and C. R. Kinjo, J. Am. Chem. Soc., 2018, 140, 652; $(b)$ T. Hynes, E. N. Welsh, R. McDonald, M. J. Ferguson and A. W. H. Speed, Organometallics, 2018, 37, 841.

5 (a) S. Miaskiewics, J. H. Reed, P. A. Donets, C. C. Oliveira and N. Cramer, Angew. Chem., Int. Ed., 2018, 57, 4039; (b) J. H. Reed, P. A. Donets, S. Miaskiewicz and N. A. Cramer, Angew. Chem., Int. Ed., 2019, 58, 8893.

6 Y.-C. Lin, E. Hatzakis, S. M. McCarthy, K. D. Reichl, T.-Y. Lai, H. P. Yennawar and A. T. Radosevich, J. Am. Chem. Soc., 2017, 139, 6008.

7 D. M. C. Ould and R. L. Melen, Chem. - Eur., J., 2018, 24, 15201.

8 J. Zhang, J.-D. Yang and J.-P. Cheng, Angew. Chem., Int. Ed., 2019, 58, 5983.

9 (a) Y.-C. Chang, Y.-C. Lee, M.-F. Chang and F.-E. Hong, J. Organomet. Chem., 2016, 808, 23-33; (b) CSD refcode TABTAU.

10 C. B. Provis-Evans, E. A. C. Emanuelsson and R. L. Webster, Adv. Synth. Catal., 2018, 360, 3999.

11 C. C. Chong, B. Rao and R. Kinjo, ACS Catal., 2017, 7, 5814.

12 J. W. Dube, G. J. Farrar, E. L. Norton, K. L. S. Szekeley, B. F. T. Cooper and C. L. B. Macdonald, Organometallics, 2009, 28, 4377.

13 S. Burck, D. Gudat, M. Nieger, Z. Benkö, L. Nyulászi and D. Szieberth, Z. Anorg. Allg. Chem., 2009, 635, 245.

14 Compound 2 b was crystalized from ethyl acetate/hexanes as a $1: 1$ solvate with ethyl acetate. The ethyl acetate is not shown in the ORTEP in Scheme 3 for clarity.

15 B. S. N. Huchenski and A. W. H. Speed, Org. Biomol. Chem., 2019, $17,1999$.

16 T. L. Lundrigan, E. N. Welsh, T. Hynes, C.-H. Tien, M. R. Adams, K. R. Roy, K. N. Robertson and A. W. H. Speed, J. Am. Chem. Soc., 2019, 141, 14083. 